\title{
Stigma Negatif terhadap Pengguna Cadar dikalangan Mahasiswi Universitas Negeri Padang
}

\author{
Tika Nofalia \\ Prodi Pendidikan Pancasila dan Kewarganegaraan \\ FIS Universitas Negeri Padang \\ E-mail: novaliatika6@gmail.com
}

\begin{abstract}
ABSTRAK
Penelitian ini mengkaji tentang penyebab munculnya stigma negatif terhadap pengguna cadar dikalangan mahasiswa Universitas Negeri Padang, dampak stigma negatif terhadap pengguna cadar, dan upaya menghadapi stigma negatif terhadap pengguna cadar dikalangan mahasiswa Universitas Negeri Padang. Penelitian ini merupakan pelitian kualitatif dengan metode deskriptif. Metodologi kualitatif sebagai prosedur penelitian yang menghasilkan data deskriptif berupa kata-kata tertulis atau lisan dari orang-orang dan perilaku yang dapat diamati. Data dikumpulkan melalui wawancara dan pengamatan langsung kepada informan. Hasil dari penelitian ini menunjukkan penyebab munculnya stigma negatif terhadap mahasiswi bercadar yaitu pemahaman keagamaan bahwa wajah tidak termasuk aurat, dipengaruhi oleh media, anggapan masyarakat bahwa cadar tidak sesuai dengan budaya dan geografis indonesia, eksklusif/lebih tertutup, kurangnya pengetahuan masyarakat pengetahuan masyarakat tentang cadar, dan kurangnya toleransi. Dampak stigma negatif terhadap mahasiswi bercadar Universitas Negeri Padang yaitu dari dampak positif Semakin termotivasi menggunakan cadar dan menimbulkan kemandirian sikap. Sedangkan dampak negatif yaitu yaitu terasingkan dalam masyarakat, kehilangan kepercayaan diri, meninggalkan pakaian cadar, membatasi diri, dan menimbulkan ketidaknyamanan. Upaya menghadapi stigma negatif terhadap mahasiswi bercadar di UNP yaitu meningkatkan sosialisasi dilingkungan sekitar, meningkatkan keimanan, mengabaikan stigma, berperilaku baik, membuka cadar saat kondisi yang tidak mendukung, memberikan pemahaman tentang cadar dan tetap istiqomah bercadar.
\end{abstract}

Kata Kunci: cadar, stigma negatif, UNP

\section{ABSTRACT}

This study examines the causes of the emergence of negative stigma against veil users among Padang State University students, the impact of negative stigma on veil users, and efforts to deal with negative stigma against veil users among Padang State University students. This research is a qualitative research with descriptive method. Qualitative methodology as a research procedure that produces descriptive data in the form of written or spoken words from people and observable 
behavior. Data were collected through interviews and direct observation to informants. The results of this study indicate the causes of the emergence of negative stigma against veiled female students, namely religious understanding that the face does not include genitalia, influenced by the media, public perception that veils are not in accordance with Indonesian culture and geography, exclusive / more closed, lack of public knowledge of public knowledge about veils, and lack of tolerance. The impact of negative stigma on veiled students at Padang State University is from the positive impact. They are increasingly motivated to use the veil and lead to independent attitudes. While the negative impacts are being alienated in society, losing selfconfidence, leaving the veil, limiting oneself, and causing discomfort. Efforts to deal with negative stigma against veiled students at Padang State University are to increase socialization in the surrounding environment, increase faith, ignore stigma, behave well, open the veil when conditions are not supportive, provide an understanding of the veil and remain istiqomah veiled.

\section{Keywords: veil, negative stigma, UNP}

(†) (2) This work is licensed under the Creative Commons Attribution-ShareAlike 4.0 International License. (C) 2021 by author.

\section{PENDAHULUAN}

Cadar digunakan bersama jilbab sebagai penutup wajah sehingga hanya menyisakan kedua mata saja bahkan telapak tangan pun harus ditutupi. Cadar merupakan versi lanjutan dari jilbab.. Selain itu, penggunaan cadar juga sering dibarengi dengan pengaturan sikap yang membatasi penggunanya dalam melakukan interaksi terutama dengan lawan jenis yang bukan mahram demi menjaga diri dari dosa dan fitnah. Penggunaan cadar bukan sekedar cara berbusana. Ia merupakan bentuk dari ekspresi identitas keagamaan. Karena itu perdebatan tentang pemakaian cadar di kalangan muslim Indonesia muncul terkait dengan perbedaan pemahaman dalam beragama dan sekaligus terkait dengan kesesuaian cara berpakaian demikian dalam konteks Indonesia. Kontroversi penggunaan cadar ini semakin kuat terkait dengan sering munculnya para perempuan bercadar di media elektronik maupun cetak, baik offline maupun online, setiap kali ada pemberitaan tentang tersangka yang terlibat dalam tindakan terorisme.

Dalam masyarakat yang penggunaan cadar masih dilabeli stereotip negatif, keputusan mengenakan cadar pada perempuan muslim bukanlah sebuah keputusan yang mudah. Selain itu, kewajiban dalam menutup aurat yang umum diterima mayoritas muslim di Indoensia adalah jilbab. Cadar masih merupakan bentuk busana yang jarang digunakan. Karena itu, seorang perempuan 
muslim yang mengenakan cadar secara alamiah menjadi berbeda dan tergolong dalam sekelompok kecil minoritas perempuan muslim. Karena itu perlu dikaji apa yang melatarbelakangi mereka memakai cadar dengan resiko stigma yang mereka terima sebagai minoritas.

\section{METODE PENELITIAN}

Jenis penelitian yang digunakan adalah penelitian kualitatif dengan metode deskriptif. Metodologi kualitatif sebagai prosedur penelitian yang menghasilkan data deskriptif berupa kata-kata tertulis atau lisan dari orang-orang dan perilaku yang dapat diamati. Data dikumpulkan meliputi, sumber data primer yaitu melalui wawancara dan pengamatan langsung kepada informan dan sumber data sekunder yaitu melalui dokumen atau referensi-referensi yang relevan dengan penelitian ini yaitu yang membahas tentang cadar.

\section{HASIL DAN PEMBAHASAN}

\section{Penyebab Munculnya Stigma Negatif terhadap Mahasiswi Bercadar di Universitas Negeri Padang}

Penyebab munculnya stigma dari salah satu dosen di Fakultas Ilmu Sosial yaitu berasal dari pendapat dosen itu sendiri bahwa wajah bukan termasuk bagian dari aurat wanita dan termasuk juga kedua telapak tangan. Ia berpendapat bahwa cadar dapat menghambat atau menganggu proses interaksi dengan orang lain disebabkan karena tidak melihat ekspresi wajah perempuan bercadar saat proses belajar mengajar berlangsung. Kemudian pengaruh media. Seringnya muncul berita terkait dengan teroris disertai dengan perempuan bercadar yang juga ditampilkan di media sebagai anggota keluarga terduga teroris menyebabkan masyarakat memiliki stigma negatif dengan mengaitkan cadar yang dipakainya sebagai suatu ciri dari anggota kelompok teroris.

Masyarakat menganggap bahwa cadar merupakan budaya masyarakat di Arab. Wanita bercadar dianggap sebagai peniru budaya luar karena cadar tidak sesuai dengan iklim di Indonesia. Namun bagi sebagian umat Islam menganggap bahwa cadar adalah perintah dalam agama untuk melakukakn ketaatan. Perempuan bercadar juga dipandang sebagai pribadi yang individual dan menutup diri dari lingkungan sosial masyarakat. Disebabkan karena perempuan bercadar dipandang tertutup, jarang berkomunikasi dan bergaul dan lebih banyak berada dirumah jarang bergaul dengan masyarakat sekitar.

Dampak lain penyebab munculnya stigma yaitu kurangnya pengetahuan masyarakat mengenai cadar, sehingga masyarakat menginterpretasikan cadar menjadi negatif. Masyarakat hanya mengenal cara berpakaian yang biasa terlihat baik itu pakaian berjilbab yang kurang tertutup maupun tidak tertutup. Kurangnya rasa toleransi masyarakat dalam menerima perbedaan membuat 
cadar mendapatkan stigma negatif, dan wanita bercadar dianggap ingin tenar dengan cara berpakaian berbeda dari mayoritas.

\section{Dampak stigma negatif terhadap pengguna cadar dikalangan mahasiswi bercadar UNP}

Stigma-stigma negatif yang menyerang diri mahasiswi bercadar memberikan dampak-dampak yang dirasakan oleh mahasiswi bercadar, baik dampak positif dan negatif. Dampak positif yang pertama yaitu motivasi menggunakan cadar. Partisipan mengatakan bahwa dengan adanya stigma negatif tentang cadarnya ia merasakan stigma tersebut memberi motivasi untuk istiqomah dalam bercadar, karena ia menganggap stigma tersebut sebagai sebuah tantangan. Bercadar diartikan sebagai suatu bentuk dalam menjalan ajaran agama yaitu menutup aurat sehingga ia menganggap bahwa stigma tersebut adalah suatu ujian agar ia tahu seberapa kokoh ia dalam melaksanakan ajaran agama.

Dampak dari stigma negatif terhadap pengguna cadar selanjutnya adalah munculnya sikap lebih mandiri didalam diri pengguna cadar. Stigma negatif yang mereka terima mampu menumbuhkan rasa sikap mandiri didalam diri wanita bercadar, karena masyarakat yang tidak menyukainya dan menghindar darinya, menyebabkan ia melakukan sesuatu secara sendiri.

Dampak negatif yang muncul yaitu terasingkan dalam masyarakat. Keberadaan perempuan bercadar yang masih minoritas menyebabkan masyarakat berpandangan yang kurang baik terhadap mereka, sehingga penggunaan cadar berdampak kepada kehidupan sosial perempuan bercadar berupa adanya pandangan berbeda dari masyarakat sehingga menyebabkan ia lebih nyaman melakukan aktivitas secara sendiri. Dan berada di tengah-tengah masyarakat yang mayritas bercadar membuat mereka diasingkan karena perbedaan tersebut.

Dampak lain yang dirasakan oleh pengguna cadar yaitu tidak percaya diri karena stigma tersebut menyebabkan ia tidak percaya diri ketika memakai cadar di tengah-tengah mayoritas masyarakat yang tidak bercadar. Dampak lain akibat stigma negatif yang diterima perempuan bercadar yaitu membuka kembali cadarnya. Karena stigma negatif terkait cadar terus berdatangan kepada keluarga salah satu partisipan. Dan itu membuat keluarga partisipan tidak nyaman. Akibat dari stigma yang diterima oleh partisipan membuat ia minder dan ia lebih membatasi diri dalam berinteraksi dengan lingkungan sosialnya. Partisipan membatasi diri dan bergaul dengan masyarakat yang bisa menerimanya saja

Dampak dari stigma negatif terhadap mahasiswi bercadar selanjutnya yaitu munculnya ketidaknyamanan dalam diri mahasiswi bercadar. Partisipan merasa terganggu dan membangkitkan emosionalnya dalam merespon stigma negatif yang ia terima sehingga membuatnya tidak mampu memberi respon yang baik terhadap 
stigma tersebut. Perasaan tidak terima dan merasa terganggu timbul karena stigma negatif dari masyarakat kepada partisipan. Dan perasaan tidak terima muncul dari dalam dirinya, karena menurutnya perempuan bercadar tidak seperti apa yang distigmakan

\section{Upaya menghadapi stigma negatif terhadap mahasiswi bercadar UNP}

Dalam menghadapi bermacam stigma negatif tentang cadar, upaya-upaya yang dilakukan Mahasiswi bercadar UNP berbeda-beda. Upaya yang dilakukan partisipan dalam menghadapi stigma negatif terhadap cadar yang mereka pakai yaitu dengan lebih menjalin kedekatan dengan masyarakat, yaitu dengan ikut melibatkan diri didalam kegiatan yang diadakan oleh masyarakat sehingga ia mampu memberi pembuktian kepada masyarakat bahwa dirinya tidak seperti yang distigmakan dan mengubah pikiran masyarakat yang beranggapan bahwa perempuan yang bercadar itu lebih tertutup dan tidak mau bergaul dengan lingkungan sekitar.

Upaya lain yang dilakukan partisipan dalam menghadapi stigma negatif terhadap cadarnya yaitu dengan meningkatkan keimanan kepada Tuhan dengan berserah diri atas apa yang diterimanya. Karena mereka sadar mereka hanyalah manusia biasa yang tidak terlepas dari ujian-ujian keimanan. Membiarkan atau mengabaikan stigma negatif tentang cadar, mereka menyadari bahwa pasti ada orang atau masyarakat yang tidak suka terhadap cadar yang mereka kenakan, dan mereka menganggap itu sudah menjadi hal yang biasa. Berusaha memberi kesan yang baik agar mengubah persepsi negatif terkait perempuan bercadar merupakan salah satu upaya dalam menghadapi stigma negatif cadar. Seperti bertutur kata yang baik, mencontohkan hal-hal yang baik atau bertingkah laku yang baik. Hal tersebut dilakukan agar dapat mengubah pandangan pemberi stigma. Salah satu Partisipan menggunakan masker sebagai ganti cadar guna mensiasati stigma negatif dari masyarakat. Ketika mereka tidak mendapat respon yang baik terhadap cadar yang dikenakan ketika barada dilingkungan tempat mereka tinggal Partisipan mengganti cadarnya dengan menggunakan masker. Karena mereka tidak ingin wajahnya dilihat oleh laki-laki lain Partisipan mengganti cadarnya dengan menggunakan masker ketika berada dikampungnya, itu dilakukannya karena untuk mensiasati pandangan buruk masyarakat terhadap cadarnya.

Upaya selanjutnya adalah memberi penjelasan kepada pemberi stigma tentang makna cadar. Karena stigma muncul akibat kurangnya pengetahuan masyarakat tentang cadar. Hal tersebut dilakukan agar pemberi stigma dapat memahami arti cadar sesungguhnya, sehingga dapat mengubah persepsi mereka bahwa cadar bukan sesuatu yang buruk. Saat masyarakat tidak bisa menerima kehadiran mereka Upaya yang dilakukan adalah yaitu dengan memperluas pergaulan dengan sesama pengguna cadar, itu dilakukan agar mendapatkan dukungan 
untuk bisa bertahan ditengah mayoritas dan ditengah stigma yang dihadapi. Upaya lain yang dilakukan partisipan yaitu tetap istiqomah menggunakan cadar walaupun mereka mendapatkan stigma negatif dari dosen ataupun masyarakat. Karena mereka menganggap itu adalah sebuah ujian dalam beribadah kepada Tuhan. Stigma negatif yang mereka dapatkan tidak membuat mereka goyah dalam memakai cadar.

\section{KESIMPULAN}

Berdasarkan penelitian yang telah dilakukan mengenai stigma negatif terhadap pengguna cadar dikalangan mahasiswa Universitas Negeri Padang, maka dapat disimpulkan bahwa penyebab munculnya stigma negatif terhadap mahasiswi bercadar yaitu pemahaman keagamaan bahwa wajah tidak termasuk aurat, dipengaruhi oleh media, anggapan masyarakat bahwa cadar tidak sesuai dengan budaya dan geografis indonesia, eksklusif/lebih tertutup, kurangnya pengetahuan masyarakat pengetahuan masyarakat tentang cadar, dan kurangnya toleransi. Dampak stigma negatif terhadap mahasiswi bercadar UNP yaitu dari dampak positif semakin termotivasi menggunakan cadar dan menimbulkan kemandirian sikap. Sedangkan dampak negatif yaitu terasingkan dalam masyarakat, kehilangan kepercayaan diri, meninggalkan pakaian cadar, membatasi diri, dan menimbulkan ketidaknyamanan. Adapun upaya menghadapi stigma negatif terhadap mahasiswi bercadar UNP yaitu meningkatkan sosialisasi dilingkungan sekitar, meningkatkan keimanan, mengabaikan stigma, berperilaku baik, membuka cadar saat kondisi yang tidak mendukung, memberikan pemahaman tentang cadar dan tetap istiqomah bercadar.

\section{DAFTAR PUSTAKA}

Jasperse. 2012. Identitas, yang dianggap religious diskriminasi, dan psikologis kesejahteraan di imigran Muslim wanita. Psikologi Terapan: AnUlasan Internasional. 61, 250-271

Sari dkk. 2013. Studi Fenomenologi Mengenai Penyesuaian Diri pada Wanita Bercadar. Jurnal Ilmiah Psikologi Candrajiwa, 2 (4), 116130.

Sukma Novri, Mutiara. 2016. Konstruksi Makna Cadar Oleh Wanita Bercadar Jamaah Pengajian Masjid Umar Bin Khattab Kelurahan Delima Kecamatan Tampan Pekanbaru. Jurnal IImu Komunikasi. Volume 3 nomor 1

Ratri. 2011. Cadar, Media dan Identitas Perempuan Muslim. Ejournal Universitas Diponegoro, 39 (2), 29-37 